53 Teoria..., ob. cit., tomo II, p.239.

54 Sobre os postulados de cada uma destas teorias ver nota 5 , supra.

55 Derecho Civil - Parte General. Ed. Revista de Derecho Privado, Madrid, 1978, p.748.

56 O Código Civil Italiano considera lesiva a vantagem que exceda $1 / 2$ do justo valor, o Código Francês fala em $7 / 12$.

57 O BGB fala em desproporşão manifesta, o Código Português em benefícios excessivos e injustificados, o diploma Argentino refere desproporsão chocante

58 Caio Mario $D_{2}$ Silva Pereira, Lesão nos Contratos, $4^{a}$ Cd FORENSE RI 1993, p210, afirma: Nõ será, 4 tanto, beterodoxa a idéia de analisar esse diploma (CDC) tanto, heterodoxa a inspiração da idéia força central de lesão.

59 Para um tratamento decomposto destes dois princípios que denomina básicos, ver Marques, Claudia Lima, Contratos..., ob. cit., parte II; capítulos 3 e 4 .
$60 \mathrm{~A}$ importância da lesão é tão grande que se a considera causa autônoma de revis̃̃o.

61 Neste sentido, Fontbressin, Patrick de, De L'Influence de l'acceptation du concept de prix sur l'évolution du droit des contrats in Revue Trimmestrielle de Droit Civil, année 1986, p. 655 e segs.

62 Poucos o fazem, como Aguiar Jr., Ruy Rosado de, Aspecto..., art. cit., Nader, Natal, Comentários ao Código de Defesa do Consumidor in Revista Forense, vol. 311/37, Alberto Do Amaral Jr. Proteção..., ob. cit, p.252 e Caio Mario da Silva Pereira, conforme nota 58 supra.

63 Jean Deprez. La Lésion dans les contrats aléatoires in Revue Trimez. La Lession dans les contrats aleatoires in Revue Trimmestriele Si Dreitos bisicas do cono 1955, p.1 64O texto - A modificasão das clausulas contratuais que estabelesam pres taşões desproporcionais ou sua revisão em razão de fat supervenientes que as tomem excessivamente onerosas.

65 Entre elas despontam a Pressuposição de Windscheid; a Superveniência de OSTI; a das Circunstâncias ExtraContratuais de Bruzin; a do Erro de Giovene, entre outras. 66 Le prix dans les contrats de longue durée, LGDJ, Paris, 1990, p. 148-149. Referindo-se à exigência legal da imprevisão, afirma que ... si l'on fait abstraction du débat théorique, on observe que le caractère imprévisible de l'événement, quel que soit l'angle sous lequel on l'envisage, 'est pas pris directement en considération par ledroit positif. 67 O Projeto de Código Civil que tramita no Congresso Nacional estabelece um outro elemento: $a$ extrema vantagem da outra parte. A teoria vem contemplada nos arts. 478,479 e 480 .

68 Sobre a diferença, à luz de disposições positivadas, ver Almeida Costa, Direito..., ob. cit., p. 267 e Mosset Iturraspe, Jorge, La Frustración del contrato, Rubinzal . Culzone editores, Argentina, p. 81 e segs.

69 A teoria da base subjetiva deve-se a Paul Oertmann e teve grande repercussão na Alemanha no período que se seguiu a Primeira Grande Guerra A teoria unitári é

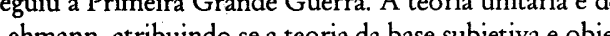
tiva (sem fusionállas) à K. Larenz.

71 71 Ha tendencias modernas que sustentam ser possivive resolver a questão dentro da teoria dos riscos, afastandose a tese da base do negócio. Entre elas a doutrina de FLUME, para quem pode-se discutir toda a situação superveniente tendo em conta a distribuição dos riscos. Assim, o trabalho hermenêutico para analisar o efeito das circunstâncias posteriores que incidam sobre o contrato consiste na analise da natureza do pacto e dos riscos assumidos. No mesmo sentido, Fikentscher afirma que a base da confiança contratual compreende as circunstâncias que não estão incluidas na esfera dos riscos contratuais assum dos pelas partes..., apud Denis, Philippe, Changement..., ob. cit., p. 247. Ainda, na mesma senda, este autor comenta doutrim do o autor a partir de uma visão econômica do dirito, pro problema dos fatos supervenientes resolve-se pela (a) pos

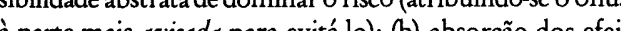
à parte mais auisuda para evitálo); (b) absorçáo dos efeitos do risco (suportando aquele que melhor absorverá economicamente, a perda) e (c) iniciativa da divisão do trabalho (tocando o ônus ao devedor pois o trabalho contratual é feito em favor do credor).

72 Sobre os dois conceitos, ver Tomasetti Jr., Alcides, Aspectos da protesão contratual do consumidor no mercado imobiliário urbano. Rejeição das cláusulas abusivas pelo $d i$ reito comum in Direito do Consumidor 2/52.

\title{
Os contratos de "shopping centers" e as cláusulas abusivas
}

Zuleika Pinto Costa Vargas

Mestranda em Direito pela Universidade Federal do Rio Grande do Sul.

Procuradora de Justiça.

SUMÁRIO Introdução; 1 - As clausulas abusivas: A - Noçôes Gerais; 1 - 5 - Busca de uma síntese significativa; II - Os contrato Abuso do Direito; - Teoria da lesão; - Teos; A - Dúplice Fixação de Aluguel; B - A Renovação de Aluguel; C - A Revisão do Aluguel; D - Res Sperata; E - Outras cláusulas; Conclusão.

\section{Introdução}

1. A evolução econômica e social de nossos dias, com a mudança da fisionomia das relações sociais, deu lugar ao aparecimento, no campo do direito contratual, de figuras novas de contrato, ainda não conhecidas, ou que ain da não penetraram com o devido aprofundamento na sistemática de nossa contratualística.

Dentre eles situamos os contratos de shopping centers como uma figura nova dentro da economia brasileira que tem suscitado muitas questões, algumas das quais pretendemos abordar no presente estudo.

2. No estudo da evolução da noção de contrato merece destaque especial e inicial o período histórico relativo ao predomínio da idéia de autonomia da vontade, tal a sua importância, refletida até nossos dias.

"A vontade é a causa primeira do direito": é assim que se enuncia o credo filosófico e jurídico dos séculos XVII e XIX ${ }^{1}$. Segundo tal concepção, na base da estrutura social está o indivíduo, ou seja, uma vontade livre.

Vincula-se o dogma da autonomia da vontade a um posicionamento básico sócio-político - o liberalismo.

Constata-se, então, que o entendimento dos juristas franceses e alemães é comum: a vonta- de humana é o fator essencial na criação, modificação e extinção dos direitos e obrigações.

Duas foram, porém, as teorias que procuraram explicar o primado da vontade: a teoria da vontade e a teoria da declaração.

3. A Willenstheorie tem um Thibaut, Puchta, Savigny, Windscheid e Zitelmann os mais importantes propugnadores, entre outros.

Segundo Savigny, chama-se declaração de vontade e espécie dos fatos jurídicos que não são apenas livres, mas que, segundo a vontade do agente, têm por fim imediato criar ou extinguir uma relação jurídica.

São, pois, dois os elementos dos negócios jurídicos: a vontade interna e a declaração da vontade, que devem ser, necessariamente, concordantes.

Esse fundamento leva a uma única idéia: a idéia da liberdade de contratar.

Liberdade de contratar e igualdade formal das partes eram portanto os pilares, que se completavam reciprocamente, sobre os quais se formava a asserção peremptória, segundo a qual dizer contratual equivale a dizer justo (qui dit contractuel dit juste) ${ }^{2}$.

Mas a teoria da vontade, conforme foi exposta, adequada a um sistema econômico individualista e pouco dinâmico, mostrava-se-se incapaz de satisfazer as exigências da moderna economia de massa, caracterizada pelo volu- 
me de trocas e pela impessoalidade. Assim, a doutrina alemã, preocupada em garantir a celeridade das contratações, a segurança e a estabilidade das relações, incompatíveis com a atribuição da relevância decisiva à vontade individual, construiu a teoria da declaração.

4. As exigências da produção e consumo de massa determinaram "um processo de 'objetivação', o qual tende a perder parte dos seus originais caracteres de voluntariedade" (Galgano $^{3}$

A construção desta teoria se atribui a Liebe $^{4}$. Mas é Bülow que, em 1899, elabora uma teoria geral da declaração da vontade, adotando posição oposta à dos defensores da Willenstheorie.

Para esta teoria pouco importa que a declaração corresponda ou não ao conteúdo exato da vontade, pois esta não constitui a essência do negócio jurídico, sua força criadora. A vontade interna não chega a ser sequer um elemento componente do negócio jurídico, porque não passa de um momento passageiro de sua gênese. A vontade constitui uma causa, mas não um elemento componente do negócio. Não se deve levar em conta a vontade do efeito, senão a da declaração, que é indispensável ${ }^{5}$.

A Eklarungstheorie foi o primeiro ataque ao princípio da autonomia da vontade, uma vez que nega à vontade o poder de criar direitos e obrigações, sustentado pela Willenstheorie, não se libertando, contudo, do voluntarismo 6

5. Neste século, a teoria da autonomia da vontade, vem sofrendo sérias críticas. A teoria da validade ou da confiança tem sido difundida principalmente na Alemanha e representa um abandono da posição individualista que caracterizava a Willenstheorie

A teoria da confiança, também denominada teoria do crédito social, empresta valor à aparência da vontade, princípio segundo o qua as situações aparentes prevalecem sobre a vontade real de quem, de qualquer modo, contribuiu para as criar, quando tal seja necessário para tutelar os interesses de todos quantos tenham confiado na aparência.
Tal concepção - da tutela da confiança surgiu em razão do processo social moderno, da crescente massificação dos contratos e, portanto, da predominância do momento social e a conseqüente limitação da liberdade contratual.

6. Assim, o tráfico econômico, cada mais acelerado, se vai convertendo em um tráfico de massa. Um critério de racionalização e organização empresarial conduz a uma standardização das formas contratuais. O esquema tradicional do contrato é substituído pelos contrato standard - os contratos de adesão, contratos preformulados ou contratos com condições gerais.

É neste contexto que surgem os contratos de shopping centers, celebrados por adesão à cláusulas predispostas, onde o empresário consolida uma posição negocial dominante, impondo aos locatários uma situação de sujeição, que consiste na necessidade de aderir ou não ao ato, sem possibilidade de participar na conformação de seu conteúdo.

Esta nova forma de contratar, apesar de apresentar inúmeras vantagens, acarreta problemas relativos ao equilíbrio contratual, mercê da desigualdade das posições das partes no processo formativo do contrato, oportunizando, inclusive, $a$ inserção de cláusulas excessivamente onerosas à parte que a adere, com vantagens para o predisponente - são as chamadas cláusulas abusivas.

O presente estudo pretende, numa primeira parte, apresentar noções gerais sobre as cláusulas abusivas, para, na segunda, apresentar algumas cláusulas constantes nos contratos de shopping center que, por suas características, se configuram abusivas.

\section{I - As cláusulas abusivas}

a) Noções gerais

Pode-se tomar a expressão cláusulas abusivas como sinônimas de cláusulas opressivas, cláusulas onerosas ou, ainda, cláusulas excessivas 7 .
A expressão cláusulas abusiva, embora não I imune a críticas, consagrou-se na doutrina a legislação específica das últimas décadas. Quatro teorias, na doutrina, procuraram Idamentar o controle da equivalência das stações, a fim de permitir uma proteção eficontra o desequilíbrio dos contratos: a do iquecimento sem causa, a do abuso de di:o, a da lesão e o princípio de boa fé.

\section{1 - Teoria do enriquecimento sem causa}

Primeiramente, em face do princípio mode que ninguém pode enriquecer às custas outro, a doutrina, diante do desequilíbrio prestações, viu no enriquecimento sem cauo fundamento das cláusulas abusivas. $O$ ipulante que redige cláusulas que lhe atribuvantagens excessivas, enriquece injustamenAssim, a noção de enriquecimento sem causa de corrigir a injustiça contratual.

Constata-se, entretanto, que tal noção não mite um controle do equilíbrio das prestais 8 .

Sua receptividade é, com efeito, submetida uas condições rigorosas: a ausência de causa usência de qualquer outra via de direito. Esta pla exigência, acarreta imediatamente a exsão desta técnica das relações entre contrattes. Seu caráter subsidiário, de uma parte, : confere necessariamente um domínio racontratual. De outra parte, a ausência de ssa parece excluir a ação quando o enriquenento pode se justificar por um direito oriunde uma convenção ou de uma situação lequalquer.

\section{2 - Teoria do Abuso do Direito}

Há os que entendem que a cláusula abusiva $n$ fonte inspiradora próxima à do abuso do eito. Para esses a cláusula abusiva é a manitação por excelência do abuso do direito no ntrato, pois abusa-se do seu direito quando, apesar de permanecer dentro dos seus limites, se visa um fim diferente daquele que o legislador objetivava. $\mathrm{Ou}$, ainda, aquele que tira proveito excessivo e injusto da convenção abusa de seu direito de contratar.

Segundo Pontes de Miranda, o abuso de direito, para os juristas romanos, dependia da malícia. Pelo menos, essa era a regra. Depois supunha o ato contrário à função mesma do direito exercido, bastando a intenção ou consciência do desvio. Mais tarde, esvaziado de todo elemento psicológico, o conceito fez-se mais ligado à vida social que à projeção mesma dos direitos: é suficiente que o exercício do direito se desvie 9

Malinvaud entende que o fundamento da cláusula abusiva não se refere à teoria do abuso de direito, mas pode-se interpretar como uma cláusula excessiva, muito onerosa, que comporta uma vantagem indiscriminada a favor de um dos contratantes 10

\section{3 - Teoria da lesão}

Existem outros que aproximam a cláusula abusiva da lesão.

Há lesão quando o preço de um bem ou de um serviço fixado numa convençã́o não corresponde ao seu valor venal objetivo, apreciado pelo juiz, no momento da formação do contrato ${ }^{11}$.

A cláusula abusiva é, de certa forma, lesiva. Mas a lesão funda-se em componente subjetivo (intenção de tirar proveito da situação da outra parte), constituindo vício de vontade, defeito do negócio jurídico; enquanto a cláusula abusiva tem natureza objetiva (o desequilíbrio das posições contratuais, provocado por uma das partes), sendo irrelevante a intenção ${ }^{12}$.

A cláusula abusiva, independentemente dessas possíveis conexões de natureza, tem origem autônoma, com alcance mais restrito que o abuso do direito e a lesão. Situa-se apenas no âmbito das condições gerais, sendo inaplicável às relações contratuais comuns. $O$ que é 
abusivo no contrato de adesão a condições gerais pode ser válido no contrato negociado.

\section{4 - Princípio da boa fé}

Há ainda, os que ligam a cláusula abusiva ao princípio da boa fé

Sendo uma criação do Direito, acentua Menezes Cordeiro ${ }^{13}$, a boa fé não opera como um conceito comum. Em vão se procuraria uma definição lapidar do instituto, evitadas, em geral pela metodologia jurídica, tentativas desse gênero seriam inaptas face ao alcance e riqueza reais da noção. A boa fé, segue o autor, traduz um estágio juscultural, manifesta uma Ciência do Direito e exprime um modo de decidir próprio de certa ordem sócio-jurídica.

A boa fé, como bem demonstra o autor mencionado, tem um papel fundamental no Direito, desde a fides romana até os fenômenos jurídicos novos, incluindo as condições gerais.

A boa fé apresenta-se sob dois ângulos: a boa fé subjetiva e a boa fé objetiva. A primeira, como consciência ou convicção de se ter um comportamento conforme o direito, ou como a ignorância do sujeito acerca da existência do direito do outro; a segunda, boa fé objetiva, se manifesta como um estado de ignorância valorado pelo Direito, com reflexos práticos $^{14}$ ou como norma de conduta dos indivíduos nas relações jurídicas obrigacionais. Interessam as repercussões de certos comportamentos na confiança que as pessoas neles depositam.

A boa fé objetiva importa em conduta honesta, leal, correta. É pois, a boa-fé objetiva que importa ao direito das condições gerais.

A lei alemã sobre as condições gerais dos negócios - AGB Gezetz - por assentar em uma jurisprudência experiente e não numa legislação súbita, demonstra o papel da boa fé no controle dos conteúdos contratuais, obtidos pela adesão a essas condições, razão pela qual desperta muito interesse e tem servido de modelo a várias legislações.

Essa lei, que não é só aplicável aos consumidores, articula as cláusulas abusivas somente em três preceitos (parágrafo $9^{\circ}$ a 11) que contêm uma cláusula geral proibitiva e duas listas de cláusulas abusivas (relativas e absolutas).

O parágrafo $9^{\circ}$ proclama: são ineficazes nas condições contratuais gerais as disposições que contra as regras da boa fé, prejudiquem de uma maneira desproporcionada o aderente. Considera-se prejuízo desproporcionado quando uma condição é incompatível com os princípios fundamentais da regulamentação legal do qual diverge, ou limita, de tal modo os direitos e deveres que resultem da natureza do contrato, que o fim do contrato é posto em perigo.

Os parágrafos 10 e 11 enumeram cláusulas proibidas, concretizando o que de algum modo já estava contido na menção à boa fé. Sujeitam-se estas listas a um juízo de valor no qual, novamente, intervém a boa fé.

A Lei Portuguesa (Dec.-Lei no 446/85 a exemplo da legislação alemã, consagra a cláusula geral da boa fé, no seu art. 16, determinando, ao complementá-lo, a necessária ponderação dos "valores fundamentais dos direitos, relevantes em face da situação considerada".

O Código da Defesa do Consumidor, com nítida influência do art. $9^{\circ}$ da lei alemã considera "nulas de pleno direito", as cláusulas que sejam incompatíveis com a boa fé e a eqüidade, estabeleçam obrigações iníquas, abusivas, que coloquem o consumidor em desvantagem exagerada.

O campo de aplicação desta nova lei visa atingir os contratos de consumo. Esta nova terminologia tem como mérito englobar a todos contratos civis e mesmo mercantis, nos quais, necessariamente, deve estar em um dos polos da relação um consumidor.

Embora a lei tenha o seu campo de aplicação limitado, em função do conceito de consumidor - polêmico na doutrina e na jurispru- cia - os princípios e conceitos nela contii, de qualquer forma, não podem ser relega; pelo aplicador da lei, nos conflitos acerca execução de contratos desta natureza, na dida em que integram o sistema.

\section{5 - Busca de uma síntese significativa}

João Bosco ${ }^{15}$, em sua obra, entende que los os elementos antes analisados, poderiservir para integrar o significado da exprescláusulas abusivas.

Para o autor, uma cláusula contratual poá ser tida como abusiva quando se constitui $\mathrm{m}$ abuso de direito (o predisponente das clálas contratuais, num contrato de adesão, a o direito de redigí-la, previamente; mas nete abuso se, ao redigíla o faz de forma a isar dano ao aderente). Também será consiada abusiva se fere a boa fé objetiva, pois, undo a expectativa geral, de todas e quaiser pessoas, há que haver equivalência em las as trocas. Presumir-se-á também abusiva láusula contratual quando ocorrer afronta ; bons costumes, ou quando ela se desviar do $\imath$ social ou econômico que lhe fixa o direito. aferição dessas condições não se faz, contu, através da indagação da real intenção das tes intervenientes no contrato.

Helène Bricks, a fim de conceituar cláusuzbusiva, procura demonstrar as característidessas cláusulas, a partir da análise dos contos de adesão:

a) têm elas a finalidade de reforçar a posi) do contratante economicamente forte. te, ao pré-redigir o contrato e fixar cláusulas ıdamentais, procura sempre assegurar mais ieu negócio, livrando-se dos riscos e faciliıdo-lhe a execução;

b) elas existem, em abundância, nos contos de adesão. O tráfico econômico atual ou à necessidade de se facilitar a contratação, tando as longas tratativas e discussões sobre cláusulas contratuais. Para tanto, surgiram contratos padronizados, impostos pelos tpresários com poder de coesão, em detri- mento dos consumidores. Tais contratos, em que a desigualdade das partes é flagrante, tornam-se campo fértil para a proliferação de cláusulas abusivas;

c) as características, acima apontadas, levam a uma terceira, de caráter objetivo e mensurável - que é o desequilíbrio das prestações. A acentuação da desigualdade das partes faz romper a reciprocidade, atingindo de morte a justiça comutativa. Assim, é irrelevante a "intenção de causar dano a outrem", devendo prevalecer a verificação da desigualdade, da falta correspectividade das prestações.

Após assinalar essas características, formula a autora, a sua definição:

"Dans un contrat d'adbésion conclu entre un profissionnel et un consommateur, unila. téralement prérédigé (ver fl: 15 do trabalho) par le professionnnel, est abusive tout clause entraînant, àl'avantage exclusifdu professionnel, un déséquilibre des droits et obligations des parties". 16

\section{II - Os contratos de shopping centers e} as cláusulas abusivas

Os contratos de shopping centers, assim considerados todos aqueles necessários à ativação do centro de consumo, conceituado pela maioria da doutrina como de locação e, portanto, regido pela nova lei de locações, são contratos anteriormente elaborados pelo empreendedor e oferecidos à adesão dos lojistas escolhidos.

Tais contratos, utilizando-se das condições gerais e concretizando-se através da adesão, são o campo fértil para a proliferação de cláusulas abusivas.

O predisponente aproveita-se de seu poder contratual dominante para exonerar-se de responsabilidades ou limitá-las, para atenuar obrigações ou facilitar a execução a seu cargo, ou, na perspectiva do aderente, para agravar ônus e deveres, estabelecer prazos injustos, interver ônus da prova, enfim, desequilibrar a seu favor o regulamento contratual. 
Passa-se, a seguir, ao exame de algumas cláusulas desses contratos:

\section{A - Dúplice fixação do aluguel}

Ponto de fundamental importância para o funcionamento do shopping center consiste em saber se, nas locações das unidades que o compõem, é lícito fixar o aluguel, no todo ou em parte, através de percentual, que incida sobre o faturamento da empresa locatária ou sobre os lucros por ela aferidos, com ou sem o estabelecimento de uma quantia mínima ou máxima a ser paga.

O aluguel, no contrato sob análise, é sui generis, pois se apresenta de modo dúplice, como uma parte fixa e outra variável.

O aluguel mínimo, fixo, é uma espécie de piso mercadológico nas locações do shopping center, geralmente arbitrado em função da metragem quadrada da loja.

O aluguel móvel, ou variável é devido em forma de percentual sobre o faturamento bruto.

O empreendedor, ao locar, reserva-se a prerrogativa de cobrar, mensalmente, o mais alto dentre os aluguéis apurados. Fica claro com isso, que o empreendedor deseja e, inclusive, estabelece que o lojista deve produzir ven das geradoras de aluguel percentual acima dos valores mínimos.

Parte da doutrina se insurge contra esta estipulação, vislumbrando um caráte ingerencial, chegando a indagar sobre a legitimidade deste critério, inclusive, por dar margem a uma fiscalização do locador.

Há quem vislumbre nesse alugue participativo do locador um benefício especial ou extraordinário, incompatível com a locação, que a lei de luvas teria condenado expressamen te em seu artigo 29. Tal estipulação situaria o locador na posição de verdadeiro sócio, subvertendo a estrutura da locação, transformando-a em contrato de sociedade.

O reconhecimento da abusividade de tal predisposição ficou salientado na Ap. Cível
8.835, quando o Des. Manoel Coelho, do TJDF, declarou em seu voto que o sistema engendrado pelo incorporador é uma das faces da inesgotável capacidade do capitalismo em criar formas de captação de máximo rendimento do seu capital com o menor esforço possível e sem qualquer risco. 17

De outro lado, a liberdade na determinação do aluguel tem sido aceita e reconhecida como válida pacificamente pela grande maioria da nossa doutrina, conforme manifestação de Clóvis Beviláqua, datada de 1896:

"Além da obrigação de conservar e restituiro objeto, tem o locatário a de pagar a renda ou aluguel nos prazos convencionados, ou na falta de ajuste, conforme o costume. Se havia preço estipulado e a locação foi dissolvida por culpa sua, terá de pagar como se continuasse no gozo do objeto.

$A$ renda pode consistir em dinbeiro em quaisquer outras utilidades"18

"Juridicamente irrelevante é a circunstância de, na locação percentual, variar o quantum do aluguel, pois não diz o art. 1.188 do Código Civil que à cessão do uso e gozo do bem locado deva corresponder retribuição certa, mas, sim, certa retribuição. Assim, é, também nos Códigos das demais nações, como o italiano (verso un determinato corrispettivo - art. 1.571), no alemão (o aluguel convencionado - art. 535), no suíço (moyennant un loyer - art. 253) no francês (moyennant un certain prix - art. 1.709), no português de 1867 (mediante certa retribui ção - art. 1.595), no português de 1966 (mediante retribuição - art. 1.022) etc." 19

Não é necessário que o montante do aluguel seja conhecido a priori, mas que seja determinável, através de critérios preestabelecidos.

O professor Orlando Gomes, na sua obra assim se manifesta: "A obrigação capital do locatário é pagar o aluguel. O objeto dessa prestação é, normalmente, soma de dinheiro, mas se admitem e excepcionalmente outras coisas ou, mesmo, serviços. Importa que haja retri- ıição, por ser de sua natureza a oneroside." 20

De igual modo, a jurisprudência brasileira, $\mathrm{m}$ discrepância considera válido o aluguel sim pactuado, até mesmo em locações coerciais tradicionais.

\section{B - Renovação do aluguel}

Impossível pensar em renúncia à renovao do aluguel. É a regra decorrente do tervencionismo estatal, fundado na proteção - fundo do comércio, e a lei nulifica qualter cláusula neste sentido (art. 45). ${ }^{21}$

Mesmo na vigência do dec. $24.150 / 34$, a sutrina, em sua maioria, reconhecia ao locario de unidade em shopping center o direito à novação compulsória.

A aferição das condições legais do direito : ação do usuário de unidade em shoppping nter deve ser feita objetivamente. Desde que ıcontradas, assiste-lhe direito à renovação impulsória.

O direito à renovação constitui princípio : ordem pública, nos termos do art. 30 , da tiga lei, também repetido pela nova.

Alfredo Buzaid procura classificar juridimente o direito à renovação, assim concludo: "o direito à renovação não pode ser conlerado mero direito pessoal, consistente num édito contra o locador, a fim de obrigá-lo a rmitir a fruição da coisa; é, ao contrário, um reito autônomo, cuja criação independe de na manifestação expressa de vontade do lodor; nasce da lei, desde que concorram as Indições por ela previstas. Por isso pode ser dido com o fundo de comércio, independenmente da anuência do proprietário do imó1. Tem caráter misto; funda-se numa relação rídica locativa, mas está provido de um eleento real, que opera direta e imediatamente ibre o imóvel e é oponível erga omnes. Arado de uma ação, que assegura a continuidado fundo de comércio explorado pelo locario, pode ser exercido contra o locador ou גem lhe suceda na locação, inclusive o adquirente do imóvel." 22

De outro lado, pondera Fernando Albino de Oliveira, se se admitir que o empreendedor também tem um fundo de comércio, que precisa igualmente de proteção para resguardar os interesses dos demais lojistas, pode-se admitir que tenha ele o direito de retomada diante de um lojista ineficiente, que não está mais se coadunando com a dinâmica do shopping. Com isso, o empreendedor poderia ceder o espaço a outro lojista mais eficiente. ${ }^{23}$

Daí, não ser sem razão, sustentam alguns doutrinadores, a obrigatoriedade geralmente imposta pelo locador, seja no próprio contrato ou nas Normas Gerais, no sentido de que o locatário, por certo período, supere o aluguel mínimo, pagando o percentual, sob pena de não habilitar-se à renovação de seu contrato. ${ }^{24}$

Cláudio Santos manifesta reservas em relação à eficácia desta condição. Segundo o doutrinador, pode parecer um fraudem legis, aparenta cláusula com intuito de anular um benefício conferido pela lei ao locatário e, que, no caso, é reconhecido ao lojista, segundo o texto do art. 52, $2^{\circ}$, e do art. 54, que confere o exercício das ações cujos procedimentos estão disciplinados na lei $8.245 / 91.25$

Sustentam outros doutrinadores, ainda sob a égide da lei antiga que, por não estar a locação de loja instalada em shopping center submetida ao decreto $n^{\circ} 24.150 / 34$, não teria direito à renovação da locação. Tal argumento cai por terra diante dos termos da nova lei de locações que, expressamente, inclui os shopping centers, no seu campo de aplicação.

Não se pode negar que as condições peculiares do shopping center criaram novos parâmetros na elaboração do contrato de locação, os quais merecem ser ponderados no curso da ação renovatória. O mais ostensivo deles diz respeito, justamente, à fixação do aluguel para o período a renovar.

contrato, como já se disse, não se resume em estipular o aluguel mínimo, de importância fixa, reajustado com base em índice fixado no contrato, mas estabelece uma outra 
alternativa, consistente em estipular o aluguel em função de percentagem sobre as vendas brutas. Há quem sustente que tal critério, por provocar a atualização do aluguel, torna inócua a revisão da renovatória, na parte do aluguel, pois estabelece parâmetros de avaliação permanentes, nada havendo de abusivo na cláusula que dispusesse sobre a sua renúncia.

Quanto ao aluguel percentual, alega Orlando Gomes, que este critério rejeita qualquer majoração coativa, por ser invariável o percentual convencionado. O que varia no aluguel, diz o doutrinador, é a quantidade, que é maior nos meses em que as vendas aumentam e menor quando caem. Alega, ainda, que a alteração do percentual por sentença judicial implicaria a ilícita interferência do magistrado na economia contratual, com o rompimento do equilíbrio necessário à organização. Daí defender a tese da intangibilidade do percentual. 26

Assim, para tal doutrina, a manutenção do sistema do aluguel em percentual, a par ou não de um aluguel fixo, é fundamental. Do contrá rio, como já salientado acima, poderão ser inviabilizadas as locações das lojas menos lucrativas e comprometido todo o sistema que inspirou a formação do conjunto.

Entretanto, como bem pondera Luiz Antonio da Silva, a manutenção do aluguel percentual, cujo quantum, em princípio deve ser mantido, não impede que, em casos excepcionais, uma perícia que leve em conta os critérios utilizados originariamente no estabelecimento do percentual venha a alterá-lo, para mais ou para menos, por ocasião da renovatória. 27

Caio Mário Pereira da Silva sustenta que se o juiz, ao sentenciar, entender que a aplicação dos parâmetros contratuais não atendem às exigências de justiça, poderá ser feita uma atualização. Salienta, entretanto, que não pode ser alterada a estrutura original do contrato, de vendo ser respeitada a idéia central da predominância do maior valor entre o percentual sobre o faturamento bruto e a parte fixa. ${ }^{28}$
Quanto ao aluguel mínimo, entendem alguns que, quando da renovatória, deve sofrer revisão, considerando que o contrato é dinâmico, sobretudo em se tratando de um shopping center, onde se exigem mudanças mercadológicas constantes, que podem valorizar de forma substancial a loja. Não há, sustentam, nenhuma razão de fato ou de direito que faça o aluguel mínimo imutável.

Em sentido contrário, há os que afirmam que, se houver renovatória, na sentença o juiz ficará adstrito a fixar o aluguel mínimo segundo os critérios preestabelecidos no contrato. Daí, por consequiência, defendem a licitude da cláusula de renúncia do locatário ao direito de arbitramento do aluguel no curso da renovatória. Sustentam que nada tem de imoral ou ilícita a cláusula que preestipula o critério a ser observado na fixação do aluguel mínimo e, portanto, nada tem de imoral ou ilícita a cláusula contratual mediante a qual o locatário renuncia ao arbitramento judicial do aluguel nos períodos de renovação da locação.

Sustenta Rubens Requião que "as partes ao formularem o contrato de locação inicial, sob a égide da organização do centro comercial, estabelecem previamente um sistema de revisão do aluguel mínimo, periodicamente, tendo em vista, geralmente, o índice das ORTN. Com isso o aluguel fica atualizado, ficando dispensado pelas partes o difícil mecanismo do arbitramento". Diz, ainda, o referido autor, que "isso não quer dizer que se tenham escravizado ao contrato de locação; vencido o prazo contratual, podem rejeitar sua permanência no sistema moderno e se retirar, entregando o salão onde instalaram suas lojas. O que não é de boa moral é ter concordado com o sistema e após certo tempo querer com ele romper, invocando a autoridade do magistrado." 29

Algumas opiniões são levadas a considerar tal sistema atentatório ao Direito. Entendem estes juristas não ter validade e, portanto abusiva, a cláusula que renuncia o arbitramento judicial do aluguel. Sustentam que, em consonância com o nosso sistema legal e a lei do linato vigente, ser nula a cláusula que reia ao arbitramento, não obstante prevaleI nossa legislação a liberdade contratual e ncípio da autonomia da vontade. É que os precisam estar subordinados ao namento jurídico.

revisão do valor locatício por perícia é, rdade, a essência da atual lei do inquilinato. quer subtração neste sentido consistiria a afronta à lei, principalmente, consideo-se os termos do art. 45.

onvém ressaltar que não existe uma satoriedade da revisão judicial do valor ivo, pois havendo critério predeterminaodem as partes simplesmente renovar o rato mantendo a cláusula e a forma préulada de reajustamento.

e outro lado, por ser abusiva a cláusula snúncia de arbitramento, não impedirá a :fetivação, sempre que for necessário, ou quando houver um desequilíbrio muito de, seja em favor do locador, ou do emndedor ou do locatário.

\section{¿ - Revisão do aluguel}

'revê a nova lei de locações prediais urba"Não havendo acordo, o locador, ou o rário, após três anos de vigência do contrau do acordo anteriormente realizado, poo pedir revisão judicial do aluguel, a fim ustá-lo ao preço de mercado" (art. 19). ts partes são livres para fixar o novo valor o aluguel ou alterar a forma de reajuste 18).

Is cláusulas estipuladas no começo da loo não são pétreas. Se a revisão do aluguel for obtida através do consenso, poderá itecer via judicial, a fim de adequar o aluao preço de mercado.

$A$ ação revisional é, portanto, procedimenplenamente cabível, inobstante a lementação indexatória do aluquel, já que pírito moderno desta ação não é o do simrealinhamento corretivo, mas da obtende novos patamares de valores. ${ }^{30}$ Uma coisa é o preço a acompanhar ou não a atualização da moeda, e outra, acompanhar ou não a variação do preço de mercado, que seque a lei da oferta e da procura ou da rentabilidade, coisas, entre si, bem distintas. ${ }^{31}$

A revisão, diante de razões de ordem conjuntural, como uma recessão econômica, pode dar-se a qualquer tempo, inclusive para reduzir o aluguel mínimo.

Também outras razões podem ser invocadas para a redução do aluguel mínimo, como a improficiência do empreendedor na locação dos espaços disponíveis, em especial, das chamadas lojas âncoras, que nestes sistemas são como planetas, de tal sorte a comprometer o faturamento dos lojistas instalados, ou, ainda, face ao inadimplemento do empreendedor.

As mesmas considerações expendidas, quando do exame da ação renovatória, no que diz respeito à revisão do aluguel mínimo e percentual, aplicam-se às ações revisionais.

\section{D - Res Sperata}

A res sperata, conforme já nos manifestamos em estudo anterior, seja como garantia de reserva, ou mesmo como retribuição pela cessão do fundo de comércio, não encontra qualquer óbice para a sua cobrança na contratação. A nova lei do inquilinato não veda a cobrança de qualquer quantia do locatário, na oportunidade do contrato ou do pré-contrato, na medida em que silenciou a respeito.

Entretanto o que está claramente proibido é a cobrança de remuneração de qualquer espécie, na renovação, porque o artigo 45 da nova lei preceitua serem nulas, de pleno direito, as cláusulas restritivas do direito à renovação ou que imponham obrigações pecuniárias para tanto. 32

Dentro do equilíbrio consagrado nas relações entre locador e locatário, não se encontra um lugar cômodo para uma retribuição qualquer ao locador, além do aluguel, quando referente a um novo prazo contratual. ${ }^{33}$ 
Modesto Carvalhosa, no entanto, entende que a cada renovação do contrato de locação deverá ser paga uma nova res sperata, que corresponderá então à cessão da parcela do fundo de comércio do empreendedor pelo novo prazo contratualmente previsto. ${ }^{34}$

e) Outras cláusulas, ainda, nos contratos de shopping centers são controvertidas, cujo exame será objeto de trabalho posterior, tais como a vedação da cessão da locação, a fisca lização da receita das lojas pelo locador, a que obriga o locatário ao pagamento de $13^{\circ}$ salário aos empregados e ao pessoal $\mathrm{da}$ administração do shopping center, a que obriga o locatário a contribuir para um fundo de promoções coletivas, a que subordina a vigência do contrato à sua permanência na associação, a que tem de se filiar par obter a sua condição.

\section{Conclusão}

O Direito moderno vem empreendendo esforços no sentido de tornar mais concreta igualdade entre os cidadãos. Não a igualdade formal preconizada ao tempo das primeiras codificações, mas uma igualdade material que assegure aos cidadãos um direito real, concreto.

O controle do contrato, através da identificação e banimento das cláusulas abusivas, visa a tornar efetiva a eqüidade no conteúdo das condições gerais do negócio, utilizadas no contratos padronizados, entre os quais os con tratös de shopping centers.

Tal controle levado a efeito nos contratos de shopping center visa, de um lado, conter excessivo poder econômico do empreendedor e por outro, proteger o locatário, parte mais fraca neste tipo de relação contratual. Tem po finalidade, na verdade, atingir uma situação de equilíbrio concreto entre as partes contratantes.

\section{Notas}

Rieg. Alfred. Le rôle la volonté dans la formation de acte juridique d'après les doctrines allemandes du XIX siècle. Archives de Philosofie du Droit, 1957, p. 125. Roppo, Enzo. O Contrato. Tradução: Ana Coimbra e M. Januário C. Gomes, Almedina, Coimbra, 1988, p.35Idem, p.69.

Die Stipulation und das einfache Versprechen,, 1840, p. 76, apud A. Rieg, op. cit., p. 129. Nesta obra o autor acentua que o verdadeiro elemento sobre o qual pode repousar a validade jurídica do ato não se encontra na expressão da vontade, mas em circunstâncias que a fixam. 5 Rieg, A., op. cit. p. 130 .

6 Schlossmann, em sua obra Der Vertrag, pretendendo negar o princípio da autonomia da vontade, chegou até negar as noçôes, jamais postas em duvida, como obrigacão e contrato, considerando este último ein juristisches nichts, apud in Rieg, op. cit. p. 131

7 Malinvaud, Philippe. Le Condizioni generali di contratto, in Le Condizioni Generali di contratto dirigido por Massimo bianca, Tomo II, Milano, Giuffrè, 1981, p.437.

8 Bricks, Hélène. Les Clauses Abusives. LGDJ, 1982, p.25. 9 Pontes de Miranda. Comentários ao Código de Processo Civil. Tomo I, Rio de Janeiro, 1973, p.283.

10 Ob. cit., p.437.

11 Ghestin, Jacques. Traité de Droit Civil. Les Obligations, Les Contrat: Formation. $2^{2}$ edição, LGDJ, Paris, 1988, p.

12. Lobo, Paulo Luiz Neto. Condições Gerais dos Contratos e Cláusulas Abusivas, Saraiva, São Paulo, 1991, p.

13 Menezes Cordeiro, ob. cit., vol. I, p. 17-8.

14 Idem, p. 24.

15 Leopoldino da Fonseca, João Bosco. Cláusulas Abusivas

16 Ob. cit., p. 9

17 Jurisprudência citada por Washington de Barros Monteiro, in Shopping Centers, Shopping Centers-Aspectos Jurídicos, RT, São Paulo, 1984, p.162.

18 Beviláqua Clóvis. Direito das Obrigações, Livraria 18 Beviláqua Clovis. Direito das

19 Andrade, Luis Antônio. Considerações sobre o aluguel em Shopping Centers, in Shopping Centers - Aspecos Jurídicos, ob. cit., p. 174

20 Gomes, Orlando. Contrato. $7^{\mathrm{i}}$ ed., n ${ }^{\circ} 212$, p. 334. 21 Santos, Cláudio. A Locação de espaço em Shopping Centers, in RT 680, p.19.

22 Buzaid, Alfredo. Da Ação Renovatória, $2^{2}$ edição, Saraiva, São Paulo, 1981, v.1, p.174

23 Oliveira, Fernando Albino. Fundo de Comércio em Shopping Centers, in Shopping Centers - Questões Jurídicas, Saraiva, São Paulo, 1991, p. 75. ste sentido José da Silva Maquiera, Shopping Centers gas e novas apreciações, idem, ob. cit., p. 152

J. cit., p. 16.

omes, Orlando. Perfil Jurídico de um Shopping $r$, in Shopping Center Aspectos Jurídicos, ob. cit.,

ıdrade. Luís Antônio de, ob. cit., p. 181.

reira. Caio Mário da Silva. Shopping Centers Organ econômica e disciplina jurídica, in Shopping Centers tos Jurídicos, ob. cit., p. 86

quiâo, Rubens, ob. cit., p. 141-143. No mesmo senoão Carlos Pestana Aguiar, idem, p.195.

aquiera, Jose da Silva, ob. cit., p.154.

slmonte, Alexandre Agra. Natureza Jurídica do

ping Centers, Lumen Juris, Rio de Janeiro, 1989,

ntos, Cláudio, ob. cit., p.19.

zuiar Silva, João Carlos Pestana. Anotações sobre o

o jurídico dos Shopping Centers, in Shopping

tões jurídicas), ob. cit., p.179.

irvalhosa, Modesto, idem, p. 175

\section{iografia}

ar Jr., Ruy Rosado - Resoluções dos Contratos por mplemento do Devedor, Aide, Rio, 1991.

ar Silva, João Carlos Pestana. Anotações sobre o to jurídico dos Shopping Centers, in Shopping Centers tões jurídicas), Saraiva, São Paulo, 1991.

sida Costa, Mário Júlio - Direito das Obrigações, :dina, Coimbra, 1991

ida Costa Mário Júlio e Menezes Cordeiro, AntoCláusulas Contratuais Gerais, Almedina, Coimbra,

sida, Carlos Ferreira de - Os Direitos dos Consumi;, Almedina, Coimbra, 1982.

,Guido-Controllo legislativo e controllo giudiziario ontratti standard - Il modelo dell'Unfair Contrats is Act, 1977, in Le Condizioni Generali di Contratto. me I, Giufrrè, Milano, 1979.

, Guido e Bessone, Mario - Tecnica e Controllo dei :ratti Standard, Maggiore, Milão, 1984.

ral Neto, Francisco dos Santos - A Autonomia pricomo princípio fundamental da ordem jurídica, in Inf. Legisl., $\mathrm{n}^{\circ}$ 102, abr./jun., 1989.

rade, Luis Antônio. Considerações sobre o aluguel Ars in Shopping Centers - Aspectos Juos, RT, 1994.

o Ines Varela, João de Matos - Das

Docte André-Jean - Les Origines

Français, LGDJ, Paris, 1969

1onte, Alexandre Agra. Natureza Jurídica dos pping Centers, Lumen Juris, Rio de Janeiro, 1989. oz, Georges - Le Contrat D'Adhésion, LGDJ, Paris,
Betti, Emilio - Teoria Geral do Negócio Jurídico, tomo I, rad. de Fernando Miranda, Coleção Coimbra, 1969. Beviláqua Clóvis Direito des Obrigacões, Livraria Magalhães, Salvador, 1896

Bobbio, Norberto - Teoria do Ordenamento Jurídico, Ed. UnB, Brasília, 1989.

Bourgoignie, Thierry - Eléments pour une théorie du droit a consommation, Story Scientia, Bruxelas, 1988.

Bricks, Hêlene - Les Clauses Abusives, LGDJ, Paris, 1982. Buzaid, Alfredo. Da Ação renovatória, v. 1, $2^{\text {a }}$ edição, Saraiva, São Paulo, 1981.

Canàris, Claus Wilhem - Pensamento Sistemático e Conceito de Sistema na Ciência do Direito, trad. A. Menezes

Cordeiro, Fundação Calouste Gulbenkian, Lisboa, 1989. Canotilho, José Joaquim Gomes - Direito Constitucional, Coimbra, 1991.

Castro y Bravo, Frederico de - Las condiciones generales de los contratos y la eficacia de las leys, Ed. Civitas, Madrid, 1987.

Cirne Lima, Ruy - Contrato e Acordo Normativo, RDCiv, São Paulo, Ano 7, 26:179/80, 1983.

Com, Salo Palo Ano 7,26 . $179 / 80$, 1983. Dir A Proção do consumidor: mportante capitulo do Direito Económico, in Revista

Couto e Silva, Clóvis Veríssimo - A Obrigação como Processo, São Paulo, Ed. Bushatsky, São Paulo, 1976. Diez-Picazo, Luis Fundamentos de Derecho Civil Patrimonial, Vol. I, Editorial Tecnos, Madrid, 1972.

Diez-Picazo, Luiz e Gullon, Antonio - Instituciones de Derecho Civil, Vol. I, Editorial Tecnos, Madrid, 1973. Fradera, Vera Jacob de - O Dever de Informar do Fabricante, in RT, 656, p.53-71.

Fraga, Francisco Jordano - La Responsabilidad Contractual, Civitas, Madrid, 1987.

Garcia-Amigo, Manuel - Clausulas Limitativas de $\mathrm{La}$ Responsabilidad Contractual, Editorial Tecnos, Madrid, 1965 .

Ghersi, Carlos Alberto - Contratos civiles e commerciales, Tomo I, Editorial Astrea, Buenos Aires, 1992.

Ghestin, Jacques - Traité de Droit Civil - Les obligations Les contrat: formation, LGDJ, Paris, 1988.

Gomes, Orlando - Transformações Gerais do Direito das Obrigações, Ed. RT, São Paulo, 1980.

Hondius, Ewoud $\mathrm{H}-11$ controllo sulle condizione general nel diritto olandese, in Le Condizioni Generali di Contratto, Tomo II, Giuffrè, Milano, 1979.

L'heurex, Nicole - Droit de la Consommation, Editions Wilson e Lafleur, Montreal, 1983.

Larenz, Karl - Derecho de Obligaciones, Trad. Jaime Santos Briz, Edersa, Madrid, 1978.

Leauté, Jacques - contrats-Types, in Revue Trimestrielle de Droit Civil, Paris, 53, 1953.

Leopoldino da Fonseca, João Bosco. Cláusulas Abusivas nos Contratos Editora Forense, São Paulo, 1993.

Lobo Paulo Luiz Neto Condič̃s Geis dos Contra-

Lobo, Paulo Luiz Neto - Condiçôes Gerais dos Cont 
Marques, Cláudia Lima - Contratos no Código de Defesa

Martins Costa, Judith - Crise e Modificação da Idéia de Contrato no Direito Brasileiro, in Direito do Consum dor, 3, Editora Revista dos Tribunais, São Paulo, 1992. Miranda, Custódio Piedade Ubaldino - Interpretação e Integração dos Negócios Jurídicos, RT, São Paulo, 1989. Mota Pinto, Carlos Alberto - Contrato de Adesão, in Revista Forense, vol. 73, p.33-43, jan./mar., 1977.

Nery, Nelson Júnior - $\mathrm{Da}$ Proteção Contratual, in Código Brasileiro de Defesa do Consumidor (Comentado pe los autores do anteprojeto), Fundação Universitária, 1991 Oliveira, Fernando Albino. Fundo de Comércio em Shopping Centers, in Shopping Centers - Questões Jurídicas, Saraiva, São Paulo, 1991.

Rieg, Alfred - Le Rôle de la volonté dans la Formation de

l'Acte Juridique d'aprés les doctrines allmenades du XIX siècle, in Archives de Philosophie du Droit, 26/126, $\mathrm{Pa}$ ris, 1987

Roppo, Enzo - O Contrato, Trad. Ana Coimbra Januário Gomes. Almedina, Coimbra, 1988. Salleiles, Raymond - De la Déclaration de Volonté, F. Pichon, Succeseur Editeur, Paris, 1901.

Santos, Cláudio. A Locação de Espaço em Shopping Centers, in RT 680, p.19.

Schwab, Dieter - Liberdade Contratual e Formação do Contratos ex vi legis, in Rev. Ajuris, 39/16.

Stiglitz, Gabriel - Proteccion Jurídica del Consumidor, Depalma, Buenos Aires, 1990.

Stolfi, Giuseppe - Teoria del Negocio Juridico, Ed. Rev. de Derecho Privado, Madrid, 1959.

Villey, Michel - Essor et D'cadence du Voluntarisme Villey, Michel - Essor et Décadence du Voluntarisme Wique, in Archives de Philosophie du Droit, $\mathrm{n}^{\circ} 4,1957$. Trad. Jose Luis Carro, Civitas, Madrid, 1982

\section{fesa de direitos coletivos e esa coletiva de direitos}

\section{i Albino Zavascki}

do TRF - $4^{a}$ Região. Professor de Processo Civil da UFRGS.

\section{ÁRIO}

rodução; II - Direitos difusos e coletivos e direitos individuais homogêneos: distinções; III - Instrumentos de de direitos coletivos. Ação Civil Pública - características gerais. Ação Popular - características gerais; IV mentos de defesa coletiva de direitos individuais (homogêneos). Substituição processual e representação. mento tradicional - o litisconsórcio ativo por representação. Novos instrumentos, por substituição processual; - Mandado de Seguranca Coletivo. Finalida - correntes de opinião. Finalidade - defesa de direitos subjetivos duais. Procedimento. Objeto de impetração e interesse jurídico Impetração por Partidos Políticos. Partidos dusis. Procedinento Obj

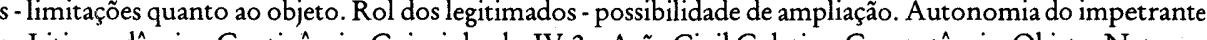
ņa tensão. Ação de cumprimento. Ação Coletiva e Açáo individual - autonomia. Limitaçôes - natureza da tutela vidên :o. Hipóteses autorizadas em Lei Constitucionalidade da legitimação. Hipótese não expressamente autorizada :i. Limites da atuação - interesses sociais. VI - Conclusões.

\section{Ibstract}

The concept of collective interests (those that in to a class of individuals, but to no one in cular) cannot be extended to individual rights , be claimed in aggregated form. Each of these ories are singled out not only by theiressential re, but also by their procedural treatment.

\section{- Introdução}

Os últimos anos marcaram no Brasil um do de importantes inovações legislativas peito dos chamados "direitos e interesses os e coletivos" e dos mecanismos de tuteletiva de direitos, destacando-se: a Lei ${ }^{\circ}$ 7, de 24.07.85 (disciplinando a chamada , civil pública"), a Constituição de 1988 gando o âmbito da ação popular, criando tandado de segurança coletivo e a imação do Ministério Público para proer ação civil pública e privilegiando a dedo consumidor) e, finalmente, o Código roteção e Defesa do Consumidor (Lei n ${ }^{\circ}$ B, de 11.09.90, que, entre outras novida- des, introduziu mecanismo de defesa coletiva para "direitos individuais homogêneos"). A entusiástica utilização, que se seguiu, dos novos mecanismos processuais, nem sempre se deu de modo apropriado, às vezes por inexperiência de seus operadores - o que é compreensível outras vezes por se imaginar, equivocadamente, que enfim se tinha em mãos o remédio para todos os males: para destravar a máquina judiciária e para salvar a sociedade de todas as agressões do Governo e dos poderosos em geral. $\hat{\mathrm{E}}$ muito salutar, por isso, o processo de revisão crítica que se vem sentindo nos últimos tempos ${ }^{1}$ no sentido de coibir exageros e assim não só preservar do descrédito, mas valorizar e aperfeiçoar esses importantes avanços no campo processual. É com esse mesmo propósito que se buscará aqui reflexão sobre tema que a experiência diária evidencia ser foco de boa parcela dos equívocos: a distinção entre os mecanismos processuais para defesa de direitos coletivos e os mecanismos para defesa coletiva de direitos.

2. Com efeito, o Código de Proteção e Defesa do Consumidor introduziu mecanismo 